\title{
TESTE DE ENVELHECIMENTO ACELERADO EM SEMENTES DE LENTILHA ${ }^{1}$
}

\author{
RAQUELALVESDE FREITAS² ${ }^{2}$ WARLEYMARCOSNASCIMENTO 3
}

\begin{abstract}
RESUMO - O presente trabalho teve como objetivo verificar a eficiência do teste de envelhecimento acelerado para avaliar o vigor de sementes de lentilha. Para tanto, utilizaram-se quatro lotes de sementes de lentilha, cultivar Silvina. A qualidade inicial de cada lote de sementes foi avaliada pela determinação do grau de umidade, germinação, primeira contagem de germinação, velocidade de emissão da raiz primária e emergência de plântulas em campo. $\mathrm{O}$ envelhecimento acelerado foi conduzido a $41^{\circ} \mathrm{C}$ durante 24,48 e 72 horas, com e sem uso de solução saturada de $\mathrm{NaCl}$. O experimento foi conduzido em delineamento inteiramente casualizado. $O$ teste de envelhecimento acelerado mostra-se eficiente para avaliar o vigor de sementes de lentilha: o período de 48 horas, a $41^{\circ} \mathrm{C}$ é o procedimento mais adequado para a classificação dos lotes em diferentes níveis de vigor.
\end{abstract}

Termos para indexação: Lens culinaris, vigor, qualidade fisiológica.

\section{ACCELERATEDAGING TESTON LENTIL SEEDS}

\begin{abstract}
The objective of this research was to examine the efficacy of the accelerated aging test for vigor evaluation of lentil seeds. Four seed lots of the Silvina cultivar were utilized. The initial quality of each seed lot was evaluated by seed moisture content germination at first count, speed of protrusion of primary root, and field seedling emergence. The accelerated aging test was conducted at $41^{\circ} \mathrm{C}$ for periods of 24,48 and 72 hours, by the traditional and $\mathrm{NaCl}$ saturated solution. The experiment was conducted in a completely randomized design. The saturated salt accelerated aging was efficient for vigor evaluation of lentil seeds, and the period of 48 hours at $41^{\circ} \mathrm{C}$ was considered as the most adequate procedure to assess seed vigor levels.
\end{abstract}

Index terms: Lens culinaris, vigor, physiological quality.

\section{INTRODUÇÃO}

A lentilha é uma das mais antigas leguminosas graníferas cultivadas pelo homem. Embora o Brasil apresente condições favoráveis para seu cultivo e boa aceitação no mercado, a produção brasileira de lentilha ainda é relativamente pequena, fazendo-se necessária a quase totalidade de importação para abastecer o mercado interno (Vieira et al., 2001). No ano de 2004, o Brasil importou cerca de 8,5 mil toneladas de lentilhas, em um valor de US\$ 3,8 milhões (Brasil, 2005). A Embrapa Hortaliças tem disponibilizado sementes de uma nova cultivar de lentilha adaptada às condições edafoclimáticas brasileiras bem como à tecnologia de produção (Giordano et al., 1988).

${ }^{1}$ Submetido em 22/07/2005. Aceito para publicação em 24/02/2006;

${ }^{2}$ Técnica de nível superior da Embrapa Hortaliças. Caixa Postal 218, CEP:
Dado o fato de que a utilização de sementes de alta qualidade constitui a base para elevação da produtividade agrícola, o componente fisiológico da qualidade de sementes tem sido objeto de inúmeras pesquisas, em decorrência das sementes estarem sujeitas a uma série de mudanças degenerativas após a sua maturidade. No entanto, verifica-se a escassez de pesquisas direcionadas à avaliação da qualidade fisiológica de sementes de espécies olerícolas, incluindo-se a lentilha.

A qualidade fisiológica das sementes tem sido caracterizada pela germinação e pelo vigor. Vigor de sementes pode ser definido como a soma de atributos que conferem à semente o potencial para germinar, emergir e resultar

70.359-970, Brasília-DF, raquel@cnph.embrapa.br;

3Pesquisador da Embrapa Hortaliças, wmn@cnph.embrapa.br. 
rapidamente em plântulas normais sob ampla diversidade de condições ambientais. Dessa forma, o objetivo básico dos testes de vigor é identificar diferenças importantes no potencial fisiológico de lotes de sementes, especialmente daqueles que apresentam poder germinativo elevado e semelhante (Marcos Filho, 1999b).

O teste de envelhecimento acelerado tem sido um dos testes de vigor mais utilizados devido a sua aplicabilidade para sementes de diversas culturas (McDonald, 1995). Embora o teste de envelhecimento acelerado já tenha envolvido suficientemente em direção à padronização, para várias espécies, ainda há vários estudos em andamento com o objetivo de aprimorar sua metodologia (Marcos Filho, 1999a). Nesse teste, as sementes são submetidas à temperatura e umidade relativa elevadas por período relativamente curto, sendo, em seguida, colocadas para germinar. Lotes de sementes de alto vigor devem manter sua viabilidade quando submetidos a tais condições, enquanto que os de baixo vigor terão sua viabilidade reduzida (AOSA, 1983). O teste de envelhecimento acelerado foi originalmente desenvolvido para determinar o potencial de armazenamento das sementes. No entanto, além de estudos nesse sentido, também têm sido realizados trabalhos para verificar sua eficiência na avaliação do potencial de emergência das plântulas em campo. Por exemplo, Piana et al. (1995) verificaram que os resultados dos testes de envelhecimento acelerado e de frio foram os que apresentaram relação mais estreita com a emergência das plântulas de cebola em campo e com a obtenção de mudas vigorosas.

Pesquisas conduzidas com cebola (Piana et al., 1995), cenoura (Spinola et al., 1998), tomate (Rodo et al., 1998) e brócolos (Mello et al., 1999) revelaram que o teste de envelhecimento acelerado foi capaz de detectar diferenças no vigor de sementes dessas espécies.

Vários fatores afetam o comportamento das sementes submetidas ao teste, sendo o binômio temperatura e período de envelhecimento o mais estudado. O teste de envelhecimento acelerado pode ser conduzido com temperaturas entre $41 \mathrm{e}$ $45^{\circ} \mathrm{C}$, sendo que mais recentemente a maioria dos trabalhos indica o uso de $41^{\circ} \mathrm{C}$ (Marcos Filho, 1999b). No entanto, Menezes e Nascimento (1988) constataram que a temperatura de $37^{\circ} \mathrm{C}$ e o período de 72 horas foram os mais eficientes para avaliação do vigor de sementes de ervilha.

Para a maioria das hortaliças, o teste de envelhecimento acelerado pode apresentar certas limitações, como a desuniformidade de absorção de água entre as amostras, o que pode resultar em deterioração diferenciada, comprometendo os resultados pós-envelhecimento. Visando minimizar esse problema, Jianhua e McDonald (1996) propuseram a substituição de água por soluções saturadas de sais, durante a condução do teste; com esse procedimento, há redução da umidade relativa do ambiente, retardando assim a absorção de água pelas sementes.

Vale ressaltar a carência de estudos sobre procedimentos adequados para avaliação do vigor de sementes de lentilha. Dessa forma, objetivou-se nesse trabalho verificar a eficiência do teste de envelhecimento acelerado para determinação do potencial fisiológico dessas sementes.

\section{MATERIAL E MÉTODOS}

A pesquisa foi conduzida no Laboratório de Sementes da Embrapa Hortaliças, Brasília, DF, em 2004. Foram utilizadas sementes básicas de lentilha (Lens culinaris Medik) da cultivar Silvina, representadas por quatro lotes de sementes, produzidos nos anos de 2001, 2003 e 2004, submetidos aos seguintes testes:

Determinação do grau de umidade - foi adotado o método de estufa a $105 \pm 3^{\circ} \mathrm{C}$ durante 24 horas, utilizando-se duas subamostras para cada lote (Brasil, 1992). Os resultados foram expressos em porcentagem na base úmida.

Germinação - conduzido com quatro repetições de 50 sementes, em rolo de papel germitest, umedecido com água, na proporção de 2,5 vezes o peso do papel seco, a $20^{\circ} \mathrm{C}$. Foram realizadas contagens aos cinco (primeira contagem) e dez dias após a instalação do teste, conforme critérios estabelecidos pelas Regras para Análise de Sementes (Brasil, 1992). Computaram-se as porcentagens médias de plântulas normais para cada lote, nas duas contagens.

Velocidade de protrusão da raiz primária - determinada durante o teste de germinação, constou da contagem do número de sementes que apresentaram emissão da raiz primária, a cada dois dias até a estabilização. A velocidade de protrusão da raiz primária, em dias, foi calculada segundo o procedimento citado por Nakagawa (1999).

Envelhecimento acelerado - utilizou-se o procedimento proposto pela AOSA (1983) e descrito por Marcos Filho (1999a). Foram distribuídas 250 sementes sobre uma tela de alumínio, fixada em caixa plástica tipo "gerbox", contendo $40 \mathrm{~mL}$ de água. As caixas, com as sementes, foram fechadas e mantidas a $41^{\circ} \mathrm{C}$ por 24,48 e 72 horas. Ao término de cada período, as sementes foram submetidas ao teste de germinação e a avaliação da porcentagem de plântulas normais foi realizada aos cinco dias após a semeadura. Determinou-se também, o teor de água das sementes após os diferentes períodos de 
envelhecimento, visando avaliar a uniformidade das condições do teste. O teste de envelhecimento acelerado foi também realizado utilizando-se o procedimento proposto por Jianhua e McDonald (1996), substituindo-se os $40 \mathrm{~mL}$ de água adicionados em cada compartimento individual por igual quantidade de solução saturada de $\mathrm{NaCl}$ (40g de NaCl/100mL de água).

Emergência das plântulas em campo - realizado na área experimental da Embrapa Hortaliças, conduzido com quatro repetições de 50 sementes em linhas de $1,0 \mathrm{~m}$ de comprimento, espaçadas de $0,2 \mathrm{~m}$; onde foram distribuídas 50 sementes, à profundidade média de $3,0 \mathrm{~cm}$. A irrigação foi feita sempre que necessária. A avaliação da porcentagem média de emergência das plântulas foi efetuada aos 15 dias após a semeadura.

O experimento foi conduzido no delineamento inteiramente casualizado, com quatro repetições. Os dados foram submetidos aos testes de normalidade e de homogeneidade de variância, que indicaram a não necessidade de transformação. Em seguida, foram submetidos à análise de variância, sendo a comparação entre a qualidade fisiológica das sementes dos diferentes lotes efetuada pelo teste de Tukey a $5 \%$ de probabilidade.

\section{RESULTADOS E DISCUSSÃO}

Os resultados obtidos na caracterização inicial da qualidade fisiológica dos lotes de sementes estão apresentados na Tabela 1. Não foram verificadas diferenças no porcentual de germinação dos diferentes lotes de sementes, justificandose assim, a utilização de testes de vigor nesses lotes. Uma das finalidades dos testes de vigor é revelar diferenças na qualidade fisiológica, que não são detectadas no teste de germinação (Marcos Filho, 1999b). No entanto, observa-se que os

TABELA 1. Valores médios obtidos nos testes de germinação (TG), primeira contagem de germinação (PCG), velocidade de emissão da raiz primária (VERP) e emergência de plântulas em campo (EPC), em quatro lotes de sementes de lentilha.

\begin{tabular}{ccccc}
\hline Lote & TG $(\%)$ & PCG $(\%)$ & VERP (dias) & EPC (\%) \\
\hline 1 & $93 \mathrm{a}$ & $77 \mathrm{a}$ & $1,78 \mathrm{a}$ & $85 \mathrm{ab}$ \\
2 & $94 \mathrm{a}$ & $79 \mathrm{a}$ & $1,86 \mathrm{a}$ & $90 \mathrm{a}$ \\
3 & $91 \mathrm{a}$ & $77 \mathrm{a}$ & $1,79 \mathrm{a}$ & $79 \mathrm{~b}$ \\
4 & $86 \mathrm{a}$ & $74 \mathrm{a}$ & $1,82 \mathrm{a}$ & $69 \mathrm{c}$ \\
\hline CV $(\%)$ & 4,82 & 8,45 & 6,90 & 5,37 \\
\hline
\end{tabular}

Médias seguidas pela mesma letra na coluna, não diferem entre si pelo teste de Tukey, a 5\% de probabilidade. resultados dos testes de vigor conduzidos juntamente com o teste de germinação, ou seja, primeira contagem e velocidade de emissão da raiz primária proporcionaram informações semelhantes à porcentagem de germinação. Isso sugere baixa sensibilidade desses testes de vigor, não refinando as informações, além das já proporcionadas pelo teste de germinação, para a separação em diferentes níveis de qualidade fisiológica, os lotes de os lotes de sementes.

Os resultados referentes à porcentagem de emergência das plântulas em campo indicaram as sementes do lote 2 como as mais vigorosas, não diferindo, no entanto, das do lote 1; as do lote 4 foram as menos vigorosas (Tabela 1). Evidenciouse, assim, a maior sensibilidade do teste de emergência das plântulas em campo, quando comparado à primeira contagem do teste de germinação e à velocidade de protrusão da raiz primária. Dessa forma, verifica-se a importância da utilização de mais de um teste para determinar o vigor das sementes, em função da variação da eficiência dos procedimentos disponíveis, conforme destacou Marcos Filho (1999b).

Observa-se que as sementes de lentilha envelhecidas pelo método tradicional apresentaram acréscimos no grau de umidade das sementes à medida que os períodos de envelhecimento aumentaram, sendo esse incremento mais acentuado no primeiro período de envelhecimento, ou seja, após 24 horas (Tabela 2). A partir deste período, o grau de umidade das sementes continuou aumentando, porém em proporções menores, mostrando, que as sementes mais secas por apresentarem baixo potencial mátrico absorvem água rapidamente quando colocadas em atmosfera úmida (Bewley e Black, 1994). Ainda na Tabela 2, verifica-se que com a utilização de solução saturada de $\mathrm{NaCl}$, obteve-se valores de umidade inferiores aos observados para as sementes envelhecidas pelo método tradicional.

Observa-se, na Tabela 3, que, à semelhança do que ocorreu no teste de emergência das plântulas em campo, as sementes de lentilha do lote 4 submetidas ao teste de envelhecimento tradicional por 24 horas apresentaram qualidade fisiológica inferior às sementes dos demais lotes. $\mathrm{O}$ período de 48 horas de exposição, no teste tradicional, não separou os lotes quanto ao vigor, apresentando, mesma tendência dos resultados obtidos no teste de germinação e nos testes de primeira contagem e velocidade de protrusão da raiz primária (Tabela 1 ).

$\mathrm{O}$ estresse provocado pelo período de envelhecimento por 72 horas no método tradicional foi altamente drástico às sementes, levando-as à última conseqüência do processo deteriorativo, a perda total da capacidade germinativa. Ramos 
et al. (2004) constataram que o estresse provocado pelo teste de envelhecimento acelerado tradicional a $45^{\circ} \mathrm{C}$ por 48 horas foi suficiente para ocasionar a morte de sementes de rúcula. Esse efeito provavelmente deve-se ao alto teor de água atingido pelas sementes após o envelhecimento com o uso dessa temperatura. Além disso, foi observada alta quantidade de fungos ao término desse período de envelhecimento, o que não foi observado nos diferentes períodos de exposição no envelhecimento modificado (com solução saturada de $\mathrm{NaCl}$ ). Segundo Jianhua e McDonald (1996) e Rodo et al. (2000) essa seria uma das justificativas para utilização de solução saturada com $\mathrm{NaCl}$, uma vez que esse procedimento proporciona baixa umidade relativa do ar, desfavorecendo o desenvolvimento de fungos e minimizando os efeitos desses microrganismos associados às sementes sobre os resultados do teste de envelhecimento acelerado.

À semelhança do que ocorreu no teste de emergência das plântulas em campo, observa-se que, pelos resultados obtidos no teste de envelhecimento acelerado modificado durante 24 horas, as sementes do lote 4 apresentaram desempenho inferior em relação aos dos demais lotes, embora não tenha diferido das sementes do lote 3 (Tabela 3). Verificase também que, o período de 48 horas permitiu estratificar os diferentes lotes em função do vigor das sementes. Assim, observa-se uma classificação em sementes de baixo (lote 4), médio (lote 3 ) e alto vigor (lotes 1 e 2), pelos resultados obtidos no teste de envelhecimento acelerado modificado por 48 horas.

Constatou-se que o teste de envelhecimento modificado reduz a absorção de água das sementes (Tabela 2). Dessa forma, a utilização de solução saturada de $\mathrm{NaCl}$ deveria proporcionar efeitos menos drásticos do que os provocados pelo envelhecimento tradicional no que se refere ao grau de deterioração das sementes. No entanto, esse fato não foi constatado para todos os lotes nos diferentes períodos de envelhecimento, sendo que alguns lotes apresentaram resultados semelhantes nos dois tipos de envelhecimento para um mesmo período de exposição ao estresse (Tabela 3 ).

Nesse estudo, o teste de envelhecimento acelerado modificado (com solução saturada de $\mathrm{NaCl}$ ) a $41^{\circ} \mathrm{C}$ por 48 horas foi o método mais adequado para classificação dos lotes em níveis de vigor, mostrando-se como alternativa promissora para avaliação do vigor de sementes de lentilha. Maior eficiência do teste de envelhecimento acelerado com uso de solução saturada de sal na classificação de sementes com diferentes níveis de vigor também foi observado em sementes de pimentão (Panobianco e Marcos Filho, 1998), cenoura (Rodo et al., 2000), melão (Torres e Marcos Filho, 2003) e pimenta malagueta (Torres, 2005).

TABELA 2. Graus de umidade (\%) obtidos antes e após os períodos de envelhecimento acelerado tradicional (água) e com solução saturada de $\mathrm{NaCl}$, em quatro lotes de sementes de lentilha.

\begin{tabular}{|c|c|c|c|c|c|c|c|}
\hline \multirow{2}{*}{ Lote } & \multirow{2}{*}{ Umidade inicial } & \multicolumn{3}{|c|}{ Tradicional (água) } & \multicolumn{3}{|c|}{ Solução saturada $(\mathrm{NaCl})$} \\
\hline & & $24 \mathrm{~h}$ & $48 \mathrm{~h}$ & $72 \mathrm{~h}$ & $24 \mathrm{~h}$ & $48 \mathrm{~h}$ & $72 \mathrm{~h}$ \\
\hline 1 & 11,5 & 23,2 & 26,5 & 30,3 & 13,3 & 14,2 & 14,4 \\
\hline 2 & 11,4 & 22,7 & 27,2 & 30,8 & 13,3 & 14,2 & 14,6 \\
\hline 3 & 11,6 & 19,8 & 25,7 & 30,6 & 12,6 & 13,9 & 14,1 \\
\hline 4 & 11,9 & 21,8 & 27,9 & 31,0 & 13,2 & 14,1 & 14,3 \\
\hline
\end{tabular}

TABELA3. Valores médios (\%) obtidos no teste de envelhecimento acelerado tradicional (água) e com solução saturada de NaCl, em quatro lotes de sementes de lentilha.

\begin{tabular}{|c|c|c|c|c|c|c|}
\hline \multirow{2}{*}{ Lote } & \multicolumn{3}{|c|}{ Tradicional (água) } & \multicolumn{3}{|c|}{ Solução saturada $(\mathrm{NaCl})$} \\
\hline & $24 \mathrm{~h}$ & $48 \mathrm{~h}$ & $72 \mathrm{~h}$ & $24 \mathrm{~h}$ & $48 \mathrm{~h}$ & $72 \mathrm{~h}$ \\
\hline 1 & $83 \mathrm{a}$ & $60 \mathrm{a}$ & 0 & $83 \mathrm{a}$ & $84 \mathrm{a}$ & $77 \mathrm{a}$ \\
\hline 2 & $80 \mathrm{a}$ & $62 \mathrm{a}$ & 0 & $84 \mathrm{a}$ & $81 \mathrm{a}$ & $69 \mathrm{a}$ \\
\hline 3 & $78 \mathrm{a}$ & $61 \mathrm{a}$ & 0 & $77 \mathrm{ab}$ & $71 \mathrm{~b}$ & $68 \mathrm{a}$ \\
\hline 4 & $65 \mathrm{~b}$ & $56 a$ & 0 & $70 \mathrm{~b}$ & $59 \mathrm{c}$ & $56 \mathrm{~b}$ \\
\hline C V $(\%)$ & 6,17 & 6,40 & & 7,09 & 5,25 & 7,70 \\
\hline
\end{tabular}

Médias seguidas pela mesma letra na coluna, não diferem entre si pelo teste de Tukey, a 5\% de probabilidade. 


\section{CONCLUSÃO}

O teste de envelhecimento acelerado com uso de solução salina saturada mostra-se eficiente para avaliar o vigor de sementes de lentilha, e o período de 48 horas a $41^{\circ} \mathrm{C}$, é o procedimento mais adequado para a classificação dos lotes em diferentes níveis de vigor.

\section{REFERÊNCIAS}

ASSOCIATION OF OFFICIAL SEED ANALYSTS. Seed vigor testing handbook. East lansing, 1983. 88p. (Contribution, 32).

BEWLEY, J.D.; BLACK, M. Seeds: physiology of development and germination. 2. ed. New York: Plenum Press, 1994. 445p.

BRASIL. Ministério da Agricultura e Reforma Agrária. Regras para análise de sementes. Brasília: SNDA/DNDV/CLAV, 1992. $365 \mathrm{p}$.

BRASIL. Ministério do Desenvolvimento, Indústria e Comércio Exterior. Importações brasileiras 2004. Disponível em: $<\mathrm{http}: / /$ aliceweb.desenvolvimento.gov.br>. Acesso em: 29 jun. 2005.

GIORDANO, L.B.; PEREIRA, W.; LOPES, J.F. Cultivo da lentilha. Brasília: EMBRAPA/ CNPH, 1988. 3p. (Instruções Técnicas, 9).

JIANHUA, Z.; McDONALD, M.B. The saturated salt accelerated aging for small-seeded crops. Seed Science and Technology, Zürich, v.25, n.1, p.123-131, 1996.

MARCOS FILHO, J. Teste de envelhecimento acelerado. In: KRZYZANOWSKI, F.C.; VIEIRA, R.D.; FRANÇA NETO, J.B. (Ed.). Vigor de sementes: conceitos e testes. Londrina: ABRATES, 1999a. cap.3, p.1-24.

MARCOS FILHO, J. Testes de vigor: importância e utilização. In: KRZYZANOWSKI, F.C.; VIEIRA, R.D.; FRANÇA NETO, J.B. (Ed.). Vigor de sementes: conceitos e testes. Londrina: ABRATES, 1999b. cap.1, p.1-21.

McDONALD, M.B. Standardization of seed vigour tests. In: CONGRESS OF THE INTERNATIONAL SEED TESTING ASSOCIATION, 24., 1995, Copenhagen, Denmark. Proceedings... Zürich, CH-Switzerland: ISTA, 1995. p.88-97.

MELLO, S.C.; SPINOLA, M.C.M.; MINAMI, K. Métodos de avaliação da qualidade fisiológica de sementes de brócolos. Scientia Agricola, Piracicaba, v.56, n.4, p.1151-1155, 1999. Suplemento.

MENEZES, J.E.; NASCIMENTO, W.M. Teste de envelhecimento precoce em sementes de ervilha (Pisium sativum L.). Horticultura Brasileira, Brasília, v.6, n.1, p.63.1988, Resumos.

NAKAGAWA, J. Testes de vigor baseados no desempenho das plântulas. In: KRZYZANOWSKI, F.C.; VIEIRA, R.D.; FRANÇA NETO, J.B. (Ed.). Vigor de sementes: conceitos e testes. Londrina: ABRATES, 1999. cap.2, p.1-24.

PANOBIANCO, M.; MARCOS FILHO, J. Comparação entre métodos para avaliação da qualidade fisiológica de semente de pimentão. Revista Brasileira de Sementes, Brasília, v.20, n.2, p.306-310, 1998.

PIANA, Z.; TILLMANN, M.A.A.; MINAMI, K. Avaliação da qualidade fisiológica de sementes de cebola e sua relação com a produção de mudas vigorosas. Revista Brasileira de Sementes, Brasília, v.17, n.2, p.149-153, 1995.

RAMOS, N.P.; FLOR, E.P.O.; MENDONÇA, E.A.F.; MINAMI, K. Envelhecimento acelerado em sementes de rúcula (Eruca sativa L.). Revista Brasileira de Sementes, Brasília, v.26, n.1, p.98-103, 2004.

RODO, A.B.; PANOBIANCO, M.; MARCOS FILHO, J. Metodologia alternativa do teste de envelhecimento acelerado para sementes de cenoura. Scientia Agricola, Piracicaba, v.57, n.2, p.289-292, 2000.

RODO, A.B.; TILLMANN, M.A.A.; VILLELA, F.A. Testes de vigor na avaliação da qualidade fisiológica de sementes de tomate. Revista Brasileira de Sementes, Brasília, v.21, n.1, p.23-28, 1998.

SPINOLA, M.C.M.; CALIARI, M.F.; MARTINS, L.; TESSARIOLI NETO, J. Comparação entre métodos para avaliação do vigor de sementes de cenoura. Revista Brasileira de Sementes, Brasília, V.20, n.2, p.301-305, 1998.

TORRES, S.B. Envelhecimento acelerado em sementes de pimentamalagueta (Capsicum frutescens L.) Revista Ciência Agronômica, Fortaleza, v.36, n.1, p.98-104, 2005.

TORRES, S.B.; MARCOS FILHO, J. Accelerated aging of melon seeds. Scientia Agricola, Piracicaba, v.60, n.1, p.77-82, 2003.

VIEIRA, R.F.; VIEIRA, C.; VIEIRA, R.F. Leguminosas graníferas. Viçosa: UFV, 2001. 206p. 